\title{
Traceability Management for the Food Safety along the Supply Chain Collaboration of Agricultural Products
}

\author{
Yuchuan Liu ${ }^{1,}$, Hongmei Gao ${ }^{2}$ \\ ${ }^{1}$ Department of Information Management, Tainan University of Technology, Tainan, Taiwan \\ ${ }^{2}$ Department of Economic Management, Tianjin Agricultural University, Tianjin, China
}

Email address:

t00258@mail.tut.edu.tw (Yuchuan Liu), gaohongmei $a$ 126.com (Hongmei Gao)

${ }^{*}$ Corresponding author

\section{To cite this article:}

Yuchuan Liu, Hongmei Gao. Traceability Management for the Food Safety along the Supply Chain Collaboration of Agricultural Products. Agriculture, Forestry and Fisheries. Vol. 7, No. 2, 2018, pp. 58-64. doi: 10.11648/j.aff.20180702.13

Received: June 25, 2018; Accepted: July 16, 2018; Published: July 19, 2018

\begin{abstract}
The heightened awareness of food-related safety issues among food consumers drives the demand for more information about the vertical and horizontal food supply chain of food products. Transparency in the way agriculture was grown and handled throughout the supply chain process resulted in an important issue of 'traceability' in global food trade and safety. Traceability is an essential subsystem of quality management and must be managed by setting up a traceability system, which keeps the data tracking of product routes and of selected attributes. A collaborative research project for the supply and logistics of agricultural products in Tianjin was proposed recently. System analysis for the traceability information of the food supply chain is studied. Specific requirements and the system architecture for the logistic management solutions are proposed. Development of this research is crucial for both the public traceability system as well as the private traceability system. The consumers' confidence for food safety choices can hence be improved.
\end{abstract}

Keywords: Logistics Management Information System, Food Traceability, Model-Driven Business Transformation

\section{Introduction}

Traceability system is to collect all the information related to the displacement of the different products along the supply chain. This information proves essential when facing food safety crisis and allows efficiently managing the consequent product recall action. The major information technology (IT) development lines, the support potential of their integration, organizational requirements for the utilization, and possible consequences for the future organization of the agro-food sector were reviewed [1]. Food traceability requires that all stakeholders within the food supply chain, including agriculture and feed producers, food manufacturers, retailers, etc., must be able to identify the source of all raw materials and ingredients to whom the products have been sold. The food companies must apply identification systems and data handling processes and must be integrated into their quality management system. The sector encompassing IT centers ought to find a reasonable compromise between the simple, step by step passing of traceable unit IDs for the neighboring actors, and the accumulated enormously huge databases of the actors. The traceability system is to provide services for the supply chain actors on cooperative basis of the mutual interests [2]. In addition, the IT centers must support the supply chain and value chain management, as well as the work of the authorities, that are responsible for the human health. Bosona and Gebresenbet [3] summarized the literature review on the food traceability issues. The definition, driving forces, barriers, benefits, traceability technologies, improvements, and performances of food traceability system had been discussed. It was pointed out that the development of full chain food traceability system is quite complex in nature, and a deeper understanding of real processes from different perspectives such as economic, legal, technological, and social issues are essential. Opara [4] reviewed the concepts of supply chain management and traceability in agriculture and highlighted the technological 
challenges, including food product label and identification, activity/process characterization, information systems for data capture, analysis, storage and communication, and the integration of the overall traceable supply chain in implementing traceable agricultural supply chains. Wang et al. [5] addressed that the values on traceability can be integrated with the supply chain management processes to manage the business process and improve its performance.

A new model and prototype of a new Farm Information Management System, which meets the changing requirements for advising managers with formal instructions, recommended guidelines and documentation requirements for various decision-making processes, was developed [6]. Manthou et al. [7] provided empirical insights regarding the use of Internet-based applications in the agri-food supply chain by focusing on the Greek fruit canning sector. The companies' perceptions regarding perceived benefits, constrained factors and motivation factors towards the use of Internet-based applications were studied. As achieving end-to-end traceability across the supply chain is quite a challenge from a technical, a co-ordination and a cost perspective, Kelepouris et al. [8] suggested a radio frequency identification (RFID) technology and outlined both information data model and system architecture that made traceability feasible and easily deployable across a supply chain. Based on an integration of alphanumerical codes and RFID technology, the traceability system for Parmigiano Reggiano (the famous Italian cheese) was developed [9]. A PDA-based Record-keeping and Decision-support System for traceability in cucumber production was developed on Windows Mobile platform invoking a Geographic Information System (GIS) control [10]. A mobile farming information system to collect the farming data and directly transmitted to the traceability system by cell phone and two-dimensional codes was proposed in [11].

Whether or not the Food Traceability System (FTS) can decrease consumers' uncertainty and strengthen purchase intention was studied in [12] and concluded that when a fast food store adopts FTS then consumers' perceived uncertainty can be reduced and in turn strengthen their purchase intentions. Jin and Zhou [13] studied consumers' interest in the information provided through food traceability systems by examining a national representative sample of 6243 Japanese consumers since 2006 online survey. their results show that more educated females have a stronger desire to access more specific information related to fresh products. Kim and Woo [14] applied the technology acceptance model with the perceived information of food involvement by using the QR code of the traceability systems. The skill of minimizing the quantity of recalled products is applied as a measure of the performance of the traceability system [15]. The state-of-the-art review in the recent advancements of food processing and packaging industry in the fields of smart packaging and materials, automation and control technology, standards, and their application scenarios, and production management principles and their improvements were proposed [16]. The deoxyribonucleic acid (DNA) barcoding, widely used molecular-based system to identify biological specimens, for food safety and in the identification of commercial application is discussed in the review of the various latest technological advancements such as innovative implementations of RFID, allowing consumers to know the full record of the products through the smartphone, and DNA sequences analyzing for the food authenticity. [17]

The logistics and information flow play an important role in the agricultural products supply chain. Liu and Gao [18] applied the model-driven business transformation (MDBT) for the review and analysis of the logistics management of fresh agricultural products supply chain. MDBT is both a business transformation methodology and a set of innovative technologies that allow business strategies to be realized by choreographing workflow tools and human activities [19]. Specific requirements for the logistic management solutions are studied. The purpose of this research is to further provide a complete study on the food safety issues by extending the fresh agricultural products logistics. Solution architectures for the food safety supply chain will be proposed. Development of this research is crucial for the solution integration of information and logistics management in fresh agricultural products supply chain business.

\section{Service-Oriented Model-Driven Business Transformation Approach}

Model-driven business transformation, MDBT developed by IBM research, uses formal models to explicitly define the structure and behavior of a business component. These models can be employed to monitor, analyze, and improve its performance, and leverages these models in the construction of its IT systems. The framework is made up of four layers: business strategy, business operations, solution composition, and IT implementation. Each layer constitutes a different level of abstraction, performs a well-defined function, and has a different audience. The strategy layer defines the goals and objectives of the business system. The operation layer describes the operations performed by the business system to achieve the goals. The composition layer is an abstraction of the computational elements that are needed to execute the business operations. The implementation layer specifies how the computational elements are implemented on a specific IT platform. Figure 1 shows the MDBT framework, including the separation of concerns, connections between model layers, and the closed-loop architecture achieved using the business process modeling component. 


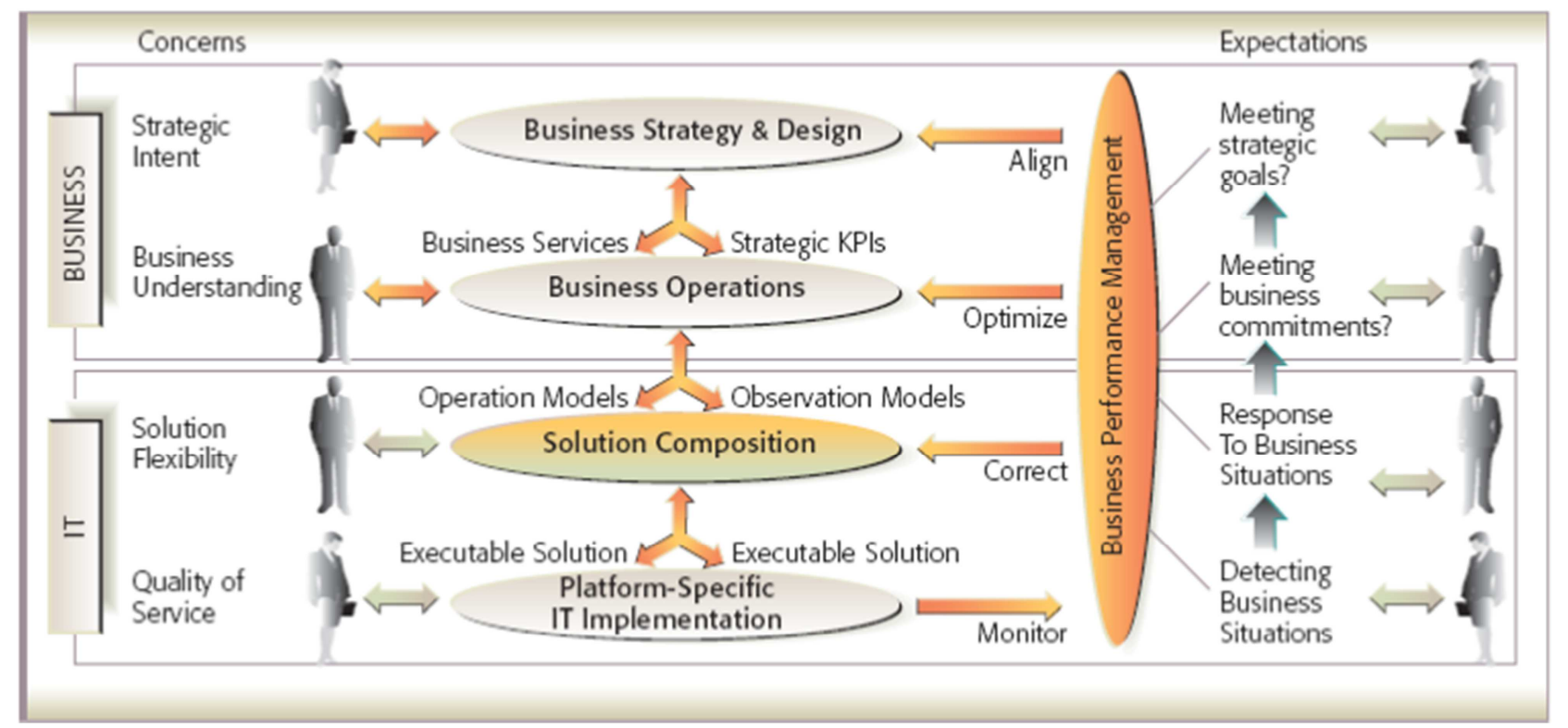

Figure 1. Model-driven business transformation framework, from [19].

In the MDBT approach, the transformation process begins with the identification of the strategic goals and objectives of the business component. This leads to a set of initiatives that support these goals. The initiatives determine the definition, analysis, optimization, and implementation of the business operations of the organization such that the strategic goals can be achieved. Formal definition of the business operations and the operational KPIs (key performance indicators) is the next step of transformation process which was referred as the business operation model. A business operation model is different from the more familiar workflow models. A business operation model, on the other hand, defines the key business artifacts and the operations performed on these artifacts. The third step of solution composition in MDBT is the judicious use of technology to support the execution of business operations. This involves the generation of a platform-independent solution composition model and the realization of this model on a specific software platform. The final step in MDBT is to create an implementation of the IT solution on a specific IT platform. Once the solution is deployed, business owners can monitor and analyze business performance using KPIs and continuously improve the models, both at the business and IT levels, based on this performance analysis.

\section{Solutions by MDBT Analysis}

The infrastructure of the fresh agricultural products logistics management can be summarized as shown in Figure 2. The solid lines stand for the logistic flow of the products, and the dashed lines are the required information flow to assure the food safety. As indicated in Figure 2, the traceability information is required during the farming process of the agricultural products. The process and ingredient information is necessary if the products are sent to the food industry for more process. The logistics information requirements, during the transportation and storage for all the supply chain stages, to ensure the completeness of the traceability management should be carefully reviewed. By applying MDBT approach, the definition of goals and objectives should be firstly analyzed in strategy layer. As the project team reviewed the current fresh agricultural products supply chain in Tianjin, the first two issues are the product loss during the logistics procedure and cost (and/or effectiveness) of the cold chain logistics. The objectives are consequently to improve the effectiveness and efficiency for fresh agricultural products logistics management. The KPIs for hardware protection can be fresh agricultural products loss during transportation, handling, and storage procedures. The KPIs for the software management can be the easy and complete access of the traceability data through the whole supply chain process, i.e., the farming data, process and ingredient information, the transportation and storage environment condition histories.

The second step of business operation analysis for MDBT is to perform the business operation. Considering the supply chain process shown in Figure 2, some observations can be made:

1. End customers can receive the fresh agricultural products via an on-line-to-off-line $(\mathrm{O} 2 \mathrm{O})$ scenario directly from the e-commerce provided by the agricultural corporations. The transportation procedures can be minimized so that the product loss caused can also be reduced.

2. The $\mathrm{O} 2 \mathrm{O}$ scenario also provides an optimized product combination both for the customer and supplier. The products delivered can be optimized according to the farming production condition and the customers' order requirement. The balance of the supply and demand can be optimized and the effectiveness of farming production can be improved. 


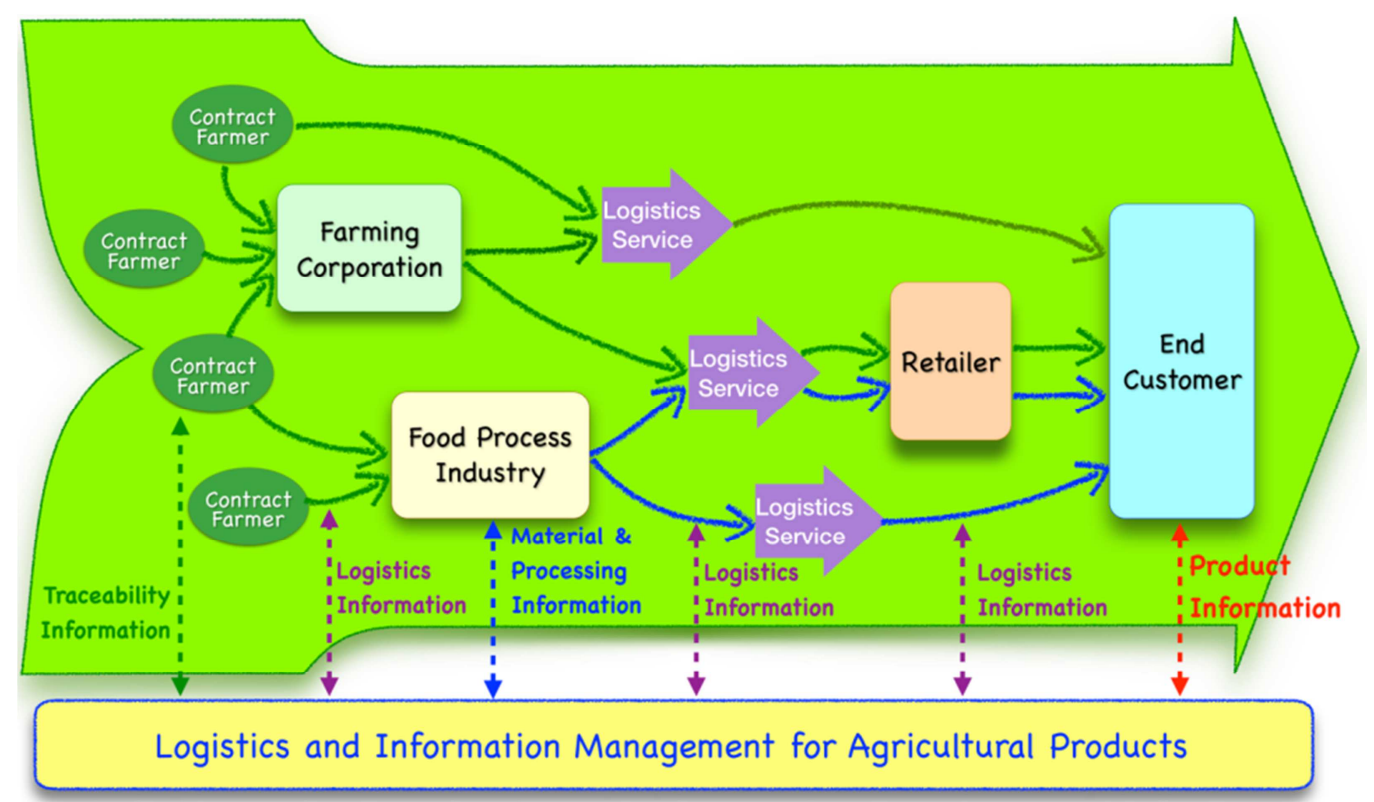

Figure 2. Infrastructure of the agricultural products logistics management.

3. The HMR, home meal replacement, is more and more popular as the necessity of ready-to-eat convenience increased significantly. The traceability information during the farming and food process are becoming an competitive issue for HMR brand marketing.

Detail solution requirements are further studied through the supply chain processes. Figure 3 shows that the logistics information flow between the supply chain enterprises can be shared and integrated for further enhancement of the supply chain management efficiency. The information system must be designed to cope with the intricate farming data, food processing information, and the rigmarole product transportation and storage information. The platform independent solution requirements are proposed in this paper. The information system should cover the farming, food processing, and logistics of the supply chain process. The specific functional requirements from configuration management analysis are listed in the following subsections.

\subsection{Farming Data Information Management}

Food traceability can be found mostly by attaching a 2-dimensional label, QR (quick response) code is the usual case, on the package of the food or agro-products. A mobile farming information system to collect the farming data and directly transmitted to the traceability system by cell phone and two-dimensional codes was proposed in [11]. The basic traceability information is consisted of the farmer, cropland, and crop planted. All the farming activities are performed on the cropland. The farming activities can be divided into three categories:

1. Farming operations for all kind of crops like seeding and pruning without the need of further attribute records.

2. Fertilizing operations which the fertilizer and amount used need to be recorded.

3. Disease prevention operations with the use and records of pesticides.

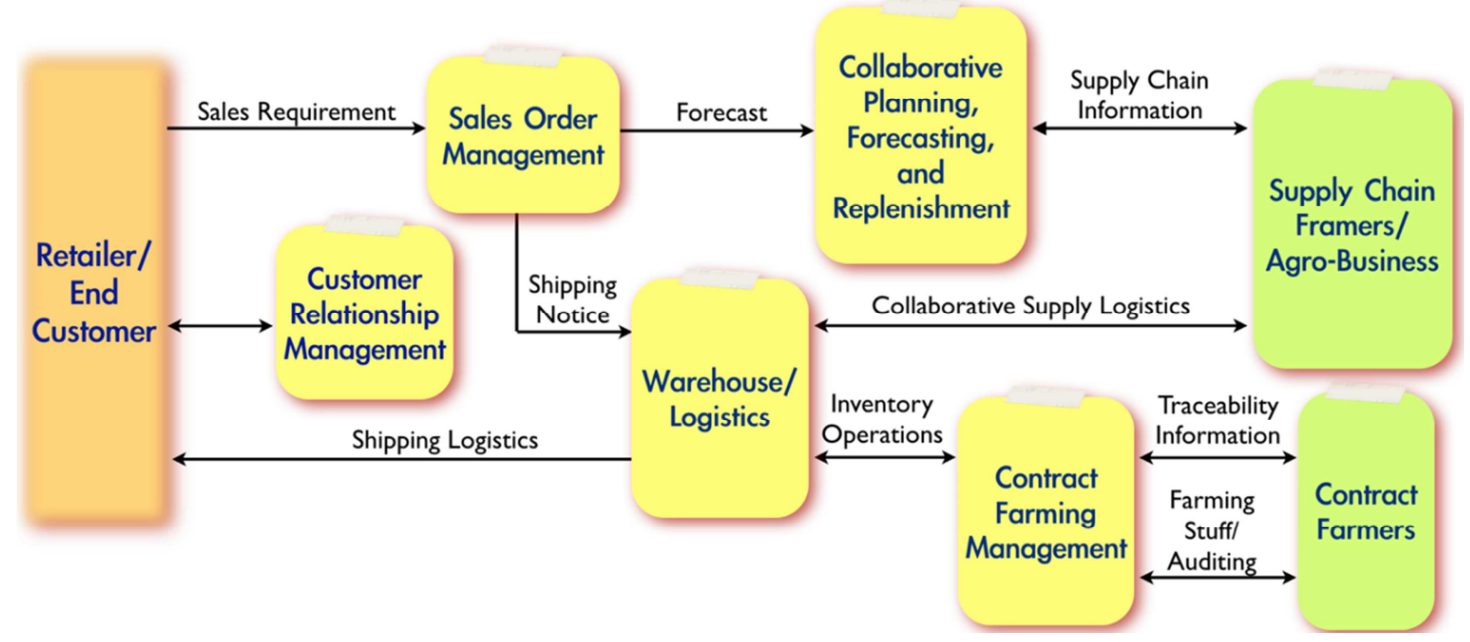

Figure 3. Architecture of the of the food supply chain information management. 
All the required operations are encoded into QR codes. Different fertilizers and pesticides are all encoded into distinct QR code. By scanning the proper QR code, the farmer can easily upload the operation messages into the data collection system. As the usage of pesticide is critical for the pesticide residual can be harmful to human, the relationship of allowable pesticide for crop is constructed to guarantee that safety of pesticide usage. The basic traceability information is consisted of the farmer, cropland, and crop planted. All the farming activities are performed on the cropland. The farming activities can be divided into three categories: the farming operations for all kind of crops like seeding and pruning without the need of further attribute records; the fertilizing operations which the fertilizer and amount used need to be recorded; and the disease prevention operations with the use and records of pesticides. All the required operations are encoded into QR codes and every farming operation is transformed into distinct QR code label. Different fertilizers and pesticides are all encoded into distinct $\mathrm{QR}$ code. By scanning the proper $\mathrm{QR}$ code, the farmer can easily upload the operation messages into the data collection system. As the usage of pesticide is critical for the pesticide residual can be harmful to human, the relationship of allowable pesticide for crop is constructed to guarantee that safety of pesticide usage.

\subsection{Food Processing Information Management}

As the rapid development and change of industrial society, modern families tend to buy prepared food as home meal replacement (HMR), like the famous Chinese Beijing ducks, instead of cooking in kitchens. For food industries to collect and keep all the food safety related processing data, it is necessary to implement the computer integrated manufacturing (CIM) system. The CIM system integrating the engineering, production control, and manufacturing by information technologies, plays as an important strategy to improve the performance of a manufacturing firm. The highly automated production processes of $300 \mathrm{~mm}$ wafer fabrication in semiconductor business is one of the most complicated CIM systems. Different types of automated material handling systems (AMHS) including, overhead shuttle vehicle (OHV), overhead hoist transporter (OHT), automatic guided vehicle (AGV), rail-guided vehicle (RGV), are employed for the inter-bay and/or intra-bay material transportation of work-in-process (WIP) to be properly processed at specified production equipment. The process equipment and AMHS are all planned, monitored, and controlled by the information systems of manufacturing execution system (MES) and material control system (MCS). The key requirements for the design and implementation of the similar CIM system in food industry can be summarized as followed.

1. Design and analysis of the AMHS system for mixed production with different types of agricultral products should be analyzed in food industry.

2. Proper production planning with the considerations of the constraints of production machines and the scheduling and dispatching rules to plan the proper daily work orders and WIPs control.

3. Detail analysis for the requirements of MES and MCS systems for the new automated process flow is necessary to assure the software systems can achieve properly the control and management purpose.

4. Developments of the new production equipment, the MES and MCS control software must be proposed. The customized information systems for production control and management must be designed and developed according to the system requirement analysis.

5. Effective project management is indispensable for the system implementation of CIM project consists of design, analysis, simulation, and verification of equipment, AMHSs, and information systems.

\subsection{Logistics Information Management t}

Venders in the fresh agricultral products supply chain are usually located far away from food industries, retailer, and customers. Transportation of fresh agricultral products can be summarized in two manners. The first type is transported directly by the food industries (or agricultural corporations). The other is to be delivered by the third-party services such as DHL. The quality of transportation and fresh agricultral products must be controlled and guaranteed during transportation. The cold chain logistics is hence become inevitable. As to provide and integrate the logistics information, the cold chain logistics vehicle need to be upgraded with information accession and transmission. Some suggestions are listed:

1. To instantly record the products receiving information at farmer site, a handhold device to input the information and transmit wirelessly to the server of the system is required.

2. The transportation management functions include: products receiving and recording, warehouse entrance check and record, and report for transportation management.

3. The storage management functions are similar to the warehouse management functions and include: warehouse receiving, automatic storage location assignment, load to storage location, unload from storage location, lot split, storage location change, inventory check, and production releasing.

\subsection{Information System Integration}

The system architecture for the integrated information management platform can be summarized as shown in Figure 4 and summarized as followed. 


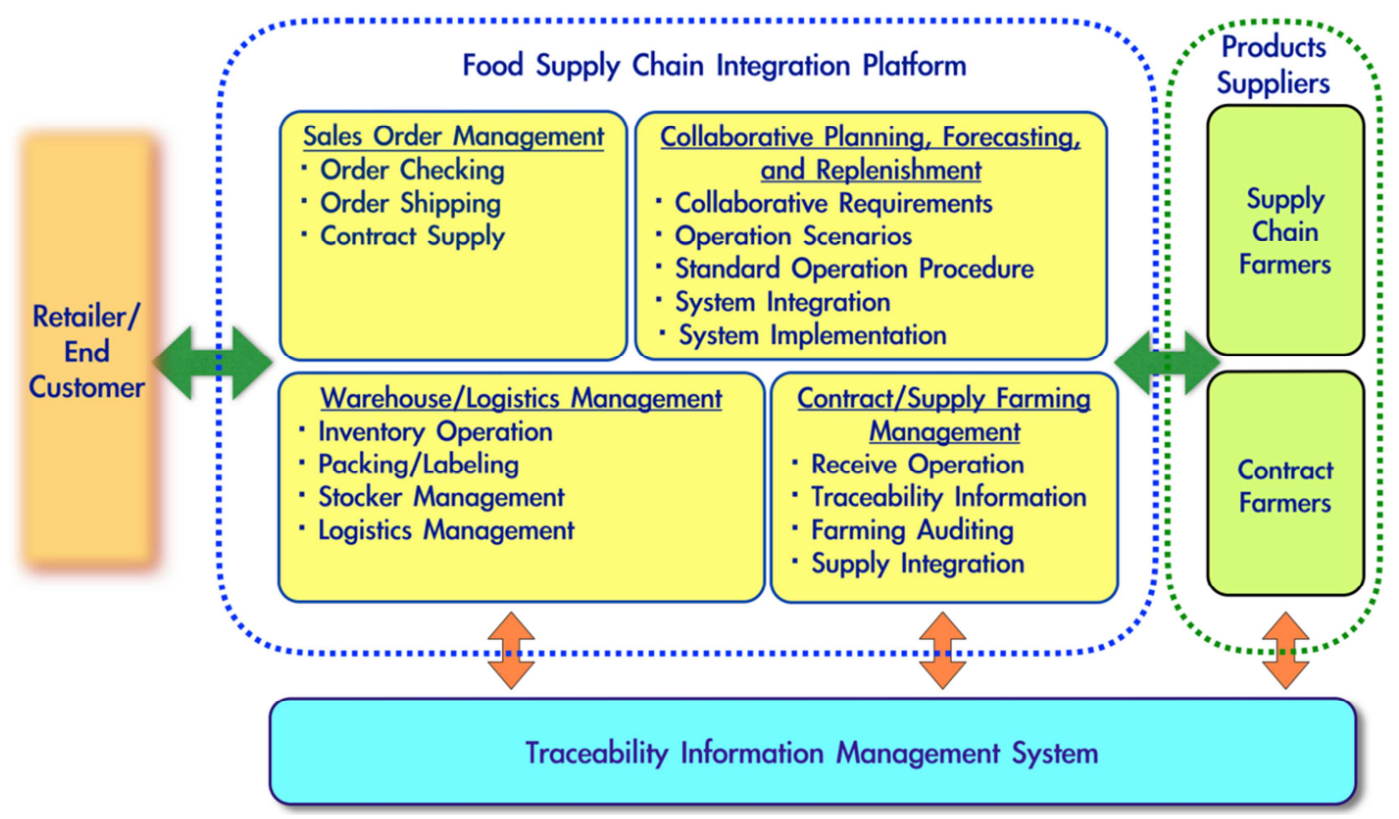

Figure 4. System integration architecture for the information management platform for traceability and logistics management of the fresh agricultural products supply chain.

1. CPFR (Collaborative Planning, Forecasting, and Replenishment) for the fresh agricultural products supply chain with the considerations of the farming production and the market requirements for proper farming control and products dispatching is necessary to minimize the unbalance of the supply-and-demand of fresh agricultural products.

2. Detail analysis for the traceability information of contract and supply farmers is necessary to assure the software systems can achieve properly the control and traceability purpose.

3. The warehouse management of fresh agricultural products is quite different from the general grocery items. The storage condition, labeling, and packing need to be carefully reviewed.

4. The integrated platform consists of different venders of the supply chain, the effective interface definition and communication protocol design are crucial for the success of the information systems.

\section{Conclusion}

The Food and fresh agricultural products supply chain is reviewed and the logistics and system analysis for integrated information management platform are studied based on the project experiences in Tianjin. System infrastructure and architecture to minimize the unbalance of the supply-and-demand of fresh agricultural products are proposed in this paper. Integration of traceability along the supply chain, form the contract farming to the storage and logistics procedure, for food safety from farm to table are considered. The requirements are summarized by the MDBT approach to provide a service-oriented-architecture solution. Some issues on the efficient traceability data collection, integrated information platform, and logistics management through the fresh agricultural products are reviewed and suggested. With the proposed functional requirements and system analysis, the results of this paper can be fruitful for the further design of the fresh agricultural products logistics information management platform systems.

\section{Acknowledgements}

This work was financially supported by the Tianjin Administration of Foreign Affairs (project no. 20181200011).

\section{References}

[1] G. Schiefer, "New technologies and their impact on the agri-food sector: an economists view," Comput. and Electron. in Agr., Vol. 43, no. 2, pp. 163-172, 2004.

[2] M. Varga and B. Csukas, "On the way toward the sector spanning agrifood process traceability," Agricultural Informatics, vol. 1, no. 1, pp. 8-18, 2010.

[3] Bosona and G. Gebresenbet, "Food traceability as an integral part of logistics management in food and agricultural supply chain," Food Control, vol. 33, pp. 32-48, 2013.

[4] L. U. Opara, "Traceability in agriculture and food supply chain: a review of basic concepts, technological implications, and future prospects," J. of Food Agric. Environ., vol. 1, no. 1, pp. 101-106, 2003.

[5] X. Wang, D. Li, and L. Li, "Adding value of food traceability to the business: a supply chain management approach," Int. J. of Serv. Oper. and Informat., vol. 4, no. 3, pp. 232-257, 2009.

[6] C. G. Sørensena, S. Fountasb, E. Nashf, L. Pesonend, D. Bochtisa, S. M. Pedersene, B. Bassoc, S. B. Blackmoreg, "Conceptual model of a future farm management information system," Comput. and Electron. in Agr., vol. 72, no. 1, pp. 37-47, 2010. 
[7] V. Manthou, A. Matopoulos, and M., "Vlachopoulou, Internet-based applications in the agri-food supply chain: a survey on the Greek canning sector," J. of Food Eng., vol. 70, no. 3, pp. 447-454, 2005.

[8] T. Kelepouris, K. Pramatari, and G. Doukidis, "RFID-enabled traceability in the food supply chain," Ind. Mana. Data Syst., vol., 107, no. 2, pp. 183-200, 2007.

[9] A. Regattieri, M. Gamberi, and R. Manzini, "Traceability of food products: General framework and experimental evidence," J. of Food Eng., vol. 81, no. 2, pp. 347-356, 2007.

[10] M. Li, J. P. Qian, X. T. Yang, C. H. Sun, and Z. T. Ji, “A PDA-based record-keeping and decision-support system for traceability in cucumber production," Comput. and Electron. in Agr., vol. 70, no. 1, pp. 69-77, 2010.

[11] Y. C. Liu and H. M. Gao, "Development and Applications of Mobile Farming Information System for Food Traceability in Health Management," in Applied Computing in Medicine and Health, edited by D. Al-Jumeily, A. Hussain, C. Mallucci, and C. Oliver, pp. 244-268, Elsevier, Aug. 2015.

[12] M. F. Chen and C. H. Huang, "The impacts of the food traceability system and consumer involvement on consumers' purchase intentions toward fast foods", Food Control, vol. 33, no. 2, pp. 313-319, Oct. 2013.

[13] S. Jin and L. Zhou, "Consumer interest in information provided by food traceability systems in Japan", Food Quality and Preference, vol. 36, pp. 144-152, Sep. 2014.

[14] Y. G. Kim and E. Woo, "Consumer acceptance of a quick response (QR) code for the food traceability system: Application of an extended technology acceptance model (TAM)," Food Research International, vol. 85, pp. 266-272, July 2016.

[15] F. Dabbene and P. Gay," Food traceability systems: Performance evaluation and optimization," Computers and Electronics in Agriculture, vol. 75, no. 1, pp. 139-146, Jan. 2011.

[16] N. Nambiar, "Trends in food packaging and manufacturing systems and technology," Trends Food Sci. Tech., vol. 21, no. 3, pp. 117-128, 2010.

[17] R. Badia-Melis, P. Mishra, and L. Ruiz-Garcia, "Food traceability: New trends and recent advances. A review," Food Control, vol. 393-401, Nov. 2015.

[18] Y. C. Liu and H. M. Gao, "System Analysis for the Traceability and Logistics Management of Fresh Agricultural Products Supply Chain," Advances in Economics, Business, and Management Research, vol. 50, pp. 100-104, Oct. 2017.

[19] S. Kumaran, "Model Driven Enterprise," Proceedings of the Global Enterprise Application Integration Summit, pp. 166180, Banf, Canada, 2004. 